\title{
O gênero debate a serviço da capacidade de análise crítica, da autonomia e do posicionamento eficaz
}

Daniela Favero Netto*

\section{Problema de Pesquisa}

É consensual a afirmação por parte de professores de todas as áreas do Ensino Fundamental e Médio que nossos alunos têm dificuldades para expressar suas ideias, formulações e opiniốes, seja por meio do texto oral, seja por meio do texto escrito. Estudos vêm sendo feitos na tentativa de diagnosticar a razão do problema, bem como de propor uma solução, inclusive em áreas de estudo como Ciências, História, Geografia, entre outras.

Os professores, que se defrontam diariamente com o desafio de contribuir com o desempenho dos alunos ao produzirem textos, veem-se em uma constante busca por respostas às seguintes questões:

- Trago exemplos de textos bons, de diversos gêneros textuais, para que meus alunos os tenham como exemplo. Por que, então, meu aluno não leva em conta o tipo de interlocutor a quem o texto se dirige?

- A leitura de jornais de grande tiragem e circulação bem como de notícias on-line são recorrentes em sala de aula, em que também são oportunizadas discussões sobre os assuntos analisados. Por que, então, meu aluno tem dificuldade para

\footnotetext{
* Professora de Língua Inglesa do CAp \UFRGS. Mestre em Teoria e Análise Linguística. E-mail:d.faveronetto@gmail.com
} 
argumentar sobre determinados temas polêmicos que vêm à tona em nosso cotidiano?

- Oriento meus alunos a partir de diversos textos de apoio de autores consagrados antes de cada produção oral ou escrita. Por que, então, meu aluno encontra dificuldades para expor seu ponto de vista e embasá-lo com um discurso sólido?

- Se ofereço ao meu aluno o contato com instrumentos que poderiam lhe proporcionar a construção de argumentos consistentes, por que insiste em utilizar uma estruturação de ideias que culmina em generalizações facilmente rebatidas pela contra-argumentação?

Pécora (1999) assinala como resposta provável à inconsistência argumentativa - a qual se caracteriza, na grande maioria das vezes, pelo uso de afirmações que recaem em lugar-comum, ou seja, generalizações reproduzidas por meio de uma linguagem consagrada, não diversificada, a qual acaba por não individualizar o produtor, que não revela esforço persuasivo sobre seu interlocutor - "a transformação das condiçôes de produção da escrita em condições de reprodução, e a transformação de seu espaço em cúmplice privilegiado de um processo de desapropriação dos sujeitos da linguagem” (PÉCORA, 1999, p. 112). O autor faz menção às condiçôes de produção escrita, mas o mesmo problema de ausência de autonomia, de falta de posicionamento, repete-se nos textos argumentativos orais de nossos alunos.

Levando em consideração a importância de se preparar nosso aluno para ter uma atuação eficaz na sociedade, este projeto quer possibilitar-lhe o exercício da expressão de suas ideias, na tentativa de melhorar sua competência argumentativa por meio da apresentação oral de seus posicionamentos via debate.

É importante ressaltar que o trabalho com oralidade em sala de aula não pode corresponder a um simples exercício da língua falada, já que o bom desempenho oral é uma exigência social. Asseveram Costa Val e Zozzoli: 
É mesmo necessário que a escola se empenhe no desenvolvimento da oralidade dos alunos, visando a possibilitar-lhes [aos alunos] fluência e desembaraço na linguagem falada em instâncias públicas, inclusive na variedade padrão formal. E é preciso também proporcionar-lhes oportunidade de aprender, entre outras habilidades linguísticas, a argumentação racional, articulada e consistente, que se formula com base na reflexão sobre um tema e se exerce deliberadamente sobre determinado público. Confirmada a necessidade, é fácil concordar com a conveniência de se começar cedo esse trabalho, explorando, desde os primeiros anos escolares, a capacidade argumentativa, digamos, "intuitiva" das crianças. (COSTA VAL; ZOZZOLI, apud RIBEIRO, 2009, p. 14).

Nesse sentido, o trabalho a ser realizado pretende orientar os alunos a desenvolver estratégias para a seleção de argumentos consistentes para defender seus pontos de vista e para a organização lógica de sua exposição. Além disso, visa a prepará-los para situações de produção de textos orais tão formais quanto textos argumentativos produzidos por meio do registro escrito.

\section{Justificativa}

A realização deste trabalho se justifica pela necessidade de se aprimorar os conhecimentos acerca do processo argumentativo por parte dos alunos da Educação Básica. Afinal, como afirma Ribeiro (2009, p. 105),

ao contrário do que se pensou durante muito tempo, os espaços de convivência cotidiana, como família, grupo de amigos, igreja, entre outros, e as relações de comunicação que se estabelecem entre eles, não são suficientes para garantir às crianças a construção de conhecimentos formais sobre a produção dos gêneros orais argumentativos de domínio público.

É, portanto, papel da escola oferecer subsídios para que os alunos desenvolvam essa competência tão necessária para uma atuação eficaz na sociedade. 


\section{Objetivos e Metas}

O trabalho com o gênero debate, a ser desenvolvido com alunos das turmas 81 e 82 do Colégio de Aplicação da UFRGS, de que trata este projeto, tem por objetivos e metas que esses alunos possam:

- Valorizar a leitura e a pesquisa como fonte de informação para embasamento de textos argumentativos.

- Desenvolver a capacidade de organização e divisão de tarefas.

- Aprofundar sua competência argumentativa com o uso de argumentos que não sejam contraditórios nem generalizações.

- Utilizar corretamente os operadores argumentativos.

- Utilizar o registro formal em texto oral, adequando-o ao gênero debate.

- Planejar um texto para ser apresentado oralmente, fazendo análise crítica de sua qualidade.

- Pensar sobre situaçôes hipotéticas de contra-argumentação, prevendo possíveis argumentos para lançar mão durante o debate.

- Resolver satisfatoriamente situações-problema que possam surgir em razão da contra-argumentação.

- Contra-argumentar adequadamente e de maneira respeitosa.

- "Valer-se da linguagem para melhorar a qualidade de suas relaçóes pessoais, sendo capazes de expressar seus sentimentos, experiências, ideias e opiniões, bem como acolher, interpretar e considerar os dos outros, contrapondo-os quando necessário.” (PCNs de Língua Portuguesa, 1997, p. 33)

- Criar uma wiki para divulgação dos debates e para comentários sobre esses.

- Produzir um documentário. 


\section{Metodologia}

É comum tratar-se o texto oral como uma produção muito diferente do texto escrito. Uma das razões possivelmente seja o fato de se associar a língua escrita, por vezes, e erroneamente, ao código a ser utilizado em contextos situacionais, em práticas sociais, em que é exigida a formalidade; e de se associar, por seu turno, a língua falada aos contextos em que a coloquialidade é permitida. No entanto, com relação à produção de textos argumentativos, há outros pontos a serem considerados no que tange tanto ao texto oral quanto ao texto escrito para que se estabeleçam diferenças a serem levadas em conta no momento da produção textual, as quais dizem respeito muito mais a outros fatores do que ao fato de serem apresentados por meio da fala ou por meio da escrita, tais como: a proximidade e o envolvimento entre os interlocutores; a situação de comunicação; o objetivo do texto, etc.

Frente a esse contexto, as práticas referentes ao trabalho que se pretende realizar levarão em conta, além de atividades de análise e de uso de operadores argumentativos, de estudo de pressuposições, entre outras marcas linguísticas de argumentação, o estudo de outros aspectos, como a finalidade da atividade, a relação entre os interlocutores, a função e o uso do gênero debate na sociedade, procurando-se aproximar esse tipo de texto falado ao "pólo da escrita formal".

O trabalho iniciará com alunos da oitava série do Ensino Fundamental e será desenvolvido também durante o primeiro ano do Ensino Médio, ou seja, terá sua conclusão quando os alunos estiverem no Ensino Médio, preparando-se para o ano em que concluirão suas atividades na escola.

Nas palavras de Ribeiro (2009, p. 17), "as crianças são capazes de argumentar desde muito cedo e [...] essa capacidade argumentativa se amplia a partir de suas experiências com práticas discursivas construídas culturalmente”. Assim, a opção por se trabalhar com alunos da oitava série deve-se ao fato de, nesta fase 
escolar, serem enfatizados gêneros textuais de tipo dissertativo (como artigos de opinião, resenhas e textos de vestibular), não à falta de maturação cognitiva de alunos de séries anteriores para trabalhar com argumentação.

O trabalho pretende se organizar de modo que, ao longo de cada ano, quatro grandes debates sejam realizados, os quais terão o envolvimento dos alunos aos quais o projeto se destina (que atuarão como debatedores, como mediadores, em grupo de pesquisa e de elaboração de argumentos e contra-argumentos), dos professores orientadores e julgadores e do público interessado em assistir aos debates.

A sequência didática que será desenvolvida tem por base a organização evidenciada por Ribeiro:

O estudo inicial, que se revela em um importante recurso para acionar o repertório de conhecimento dos alunos acerca dos gêneros em estudo; o estudo para aprofundamento, que se constitui em um momento importante na apropriação e produção dos gêneros e a última fase, estudo para revisão, que é responsável pela reflexão e reformulação das produçốes. (RIBEIRO, 2009, p. 65).

Como atividade de estudo inicial, os alunos assistirão ao filme $O$ Grande Desafio ${ }^{6}$ (dirigido por Denzel Washington), cuja temática é o poder das palavras, com enfoque no gênero debate. O objetivo, num primeiro momento, é apresentar aos alunos a dinâmica de funcionamento de um debate de opinião, cuja característica é a discussão organizada acerca de uma controvérsia sobre dado tema. Outro ponto importante é o estudo da refutação, sem a qual não há debate.

Conforme Cristóvão, Durão e Nascimento,

debater é construir, pela linguagem, intervenções que ganham o estatuto de argumentos de vários tipos, por meio de comparaçôes, por concessão,

6 Sinopse: Inspirado em uma história real, o filme conta a jornada do brilhante, mas volátil, professor Melvin Tolson (Denzel Washington) que, usa de seus métodos pouco convencionais, sua visão politica e o poder das suas palavras para motivar um grupo de alunos do Wiley College, do Texas, a participar de um campeonato de debates na Universidade de Harvard. (Disponível em: http://www.cinepop.com.br/filmes/grandedesafio.php. Acesso em: 2 de out. 2010). 
por recurso à autoridade, por exemplificação, por justificativa, por recorrer a diferentes formas de refutação, por analogias, descrições, relatos, negociação de conflitos, formas especiais de transmissão das palavras alheias, etc. (CRISTÓVÃO; DURÃO; NASCIMENTO, 2003, p. 2).

Portanto, mais um objetivo a ser atingido ainda nessa fase é evidenciar as estratégias argumentativas de que os debatedores se utilizam.

Há uma série de debates disponibilizados na Internet, os quais serão previamente selecionados e aos quais os alunos assistirão; esse recurso servirá de mote para discussão sobre mecanismos de sustentação e de refutação de posicionamentos sobre os temas discutidos.

Além disso, nesse momento do trabalho, simultaneamente será feito o estudo das marcas linguísticas da argumentação (recursos retóricos, tempos verbais, funções de tematização e rematização), em especial, dos operadores argumentativos, entre os quais, os evidenciados por Koch (1993):

- Operadores com função de ajustamento e precisão (isto é, quer dizer, ou seja, etc.);

- Operadores com função de oposição, refutação ou recusa (mas, ao contrário, contudo, etc.)

- Operadores que estabelecem hierarquia (mesmo, até, até mesmo, inclusive, etc); entre outros.

Com relação à escolha do tema, cabe salientar que ela será feita de acordo com a faixa etária e capacidade dos alunos para discorrerem sobre o assunto. Segundo Ribeiro, "os temas escolhidos não podem ser tão difíceis que os alunos não dominem, nem tão fáceis que não permitam um avanço cognitivo”. (RIBEIRO, 2009 , p. 52). Serão considerados, então, os seguintes fatores no que atine à escolha do tema:

- Dimensão psicológica: interesse dos alunos;

- dimensão cognitiva: nível de complexidade compatível com os alunos;

- dimensão social: aprofundamento crítico-social; e 
- dimensão didática: conteúdo de aprendizagem.

(DOLZ; SCHENEUWLY; DE PIETRO, 2004, apud RIBEIRO, 2009 , p. 52).

O segundo momento, o de estudo para aprofundamento, será a fase em que cada grupo de debate (o grupo contra e o grupo a favor da propositura apresentada como tema) fará a pesquisa sobre o assunto, bem como organizará seus argumentos a serem apresentados no debate. Nessa fase será quando os alunos estudarão inclusive os possíveis contra-argumentos que utilizarão para contestar os argumentos da equipe de posição contrária à sua. É importante salientar que haverá uma parte do grupo cujo enfoque será unicamente estudar o assunto e propor argumentos, já que serão escolhidos pelas próprias equipes três debatedores para cada grupo, cujo compromisso será representar sua equipe diante do auditório. Ademais, é importante aferir que cada grupo terá um professor orientador, o qual auxiliará fazendo a análise prévia dos argumentos selecionados pelo grupo e da sua organização, a fim de que possíveis equívocos ou até conflitos internos do grupo possam ser sanados antes do debate.

Após o período de organização do texto oral que será apresentado pelas equipes, o debate será realizado com a mediação de um aluno que irá se preparar para tal ofício, cuja atribuição é abrir e fechar o debate, cumprimentar o auditório, apresentar os debatedores, expor o tema, regular a dinâmica de trocas entre debatedores, e, no final do debate, organizar o momento destinado a perguntas elaboradas pelo auditório aos debatedores (RIBEIRO, 2009).

Todo o processo de estudo do tema, que culminará com o debate, será registrado por fotos (inclusive do debate), para que os participantes analisem sua postura, por vídeo, para que analisem sua performance, a fim de que possam fazer uma autocrítica que evidencie o que ficou bom e o que precisa ser melhorado, bem como as estratégias utilizadas pelos debatedores do grupo oponente que não tenham sido utilizadas por seu grupo. Enfim, 
esse é o momento de estudo para revisão, no qual se poderão reformular produções, buscando aprimoramento.

Ao fim de cada debate, portanto, haverá uma documentação para estudo, que certamente contribuirá com o preparo para o debate seguinte, que será realizado por dois novos grupos, com a mesma divisão de tarefas do grupo anterior, buscandose, sempre, que um integrante não assuma a mesma tarefa que desempenhou no debate anterior.

Um grupo de alunos será responsável pela produção de textos para serem publicados em uma wiki que será criada exclusivamente para divulgar os debates, bem como para comentar cada debate realizado, quando terão a oportunidade de trabalhar também com gêneros textuais de Internet.

Essa sequência didática será mantida em todos os debates realizados, procurando-se, a cada novo debate, aumentar o nível de exigência por parte dos professores orientadores quanto ao desempenho de cada tarefa dos integrantes da equipe, já que se espera o amadurecimento dos alunos a cada nova proposta temática (decorrente também do passar do tempo), assim como um aprofundamento teórico-prático acerca do gênero em estudo.

Ao final do trabalho, quando terão sido apresentados cerca de doze grandes debates no Colégio de Aplicação da UFRGS, os alunos, então no segundo ano do Ensino Médio, terão em suas mãos uma vasta documentação do trabalho realizado, que servirá como material para a elaboração de um documentário, em modelo de curta-metragem, que registrará os principais momentos das atividades realizadas. O documentário servirá como material de apoio para dar continuidade ao projeto, caso seja interessante para a escola, e, ainda, como uma recordação para os alunos, que estarão se despedindo das atividades escolares nos anos seguintes.

\section{Resultados e impactos esperados}

Por meio dessa prática, que exigirá que os alunos estabeleçam relações intertextuais e que produzam textos orais para 
debate de opinião, pretende-se que eles possam identificar-se como sujeitos de suas produçóes.

Ao final do trabalho, espera-se que tenham aprofundado seus conhecimentos sobre as temáticas abordadas, e que haja uma evolução no que se refere a sua competência argumentativa, a sua capacidade de elaboração de conceitos e a sua desenvoltura em processos de análise em relação a diversas áreas, já que os temas poderão abranger todas as áreas de conhecimento e que as pesquisas poderão ter a colaboração de professores das quatro áreas: Comunicação, Ciências Exatas e da Natureza, Humanidades e Expressão e Movimento.

Frente aos resultados e às expectativas referentes ao trabalho que se pretende realizar, serão brevemente pontuadas as dificuldades que poderão surgir ao longo do desenvolvimento deste projeto.

A seguir serão apresentadas as Referências básicas utilizadas na elaboração do presente projeto.

\section{Referências}

CITELLI, Adilson. Linguagem e persuasão. 8 ed. São Paulo: Ática, 2004. COSTA VAL, Maria da Graça. Redação e textualidade. 2 ed. São Paulo: Martins Fontes, 1999.

CRISTÓVÃO, Vera Lúcia Lopes; DURÃO, Adja B. de A. B. e NASCIMENTO, Elvira L. Debate em sala de aula: práticas de linguagem em um gênero escolar. In: Anais do $5^{\circ}$ Encontro do Celsul, Curitiba, 2003.

KLEIMAN, Angela. Oficina de leitura - teoria e prática. Campinas: Pontes, 1993.

KOCH, Ingedore G. Villaça. Argumentação e linguagem. 3 ed. São Paulo: Cortez, 1993.

KOCH, Ingedore G. Villaça. O texto e a construção dos sentidos. São Paulo: Contexto, 2005. 
NEVES, Maria Helena de Moura. Ensino de língua e vivência de linguagem - temas em confronto. São Paulo: Contexto, 2010.

PCN - Parâmetros curriculares nacionais - Língua portuguesa. Secretaria de Educação Fundamental. Brasília: MEC/SEF, 1997.

PCN - Parâmetros curriculares nacionais - Língua portuguesa. Secretaria de Educação Fundamental. Brasília: MEC/SEF. Versão online. Disponível em: http://portal.mec.gov.br/seb/arquivos/pdf/portugues. pdf. Acesso em: 15 de set. 2011.

PÉCORA, Alcir. Problemas de redação. 5 ed. São Paulo: Martins Fontes, 1999.

RIBEIRO, Roziane Marinho. A Construção da argumentação oral no contexto de ensino. São Paulo: Cortez, 2009.

WASHINGTON, Denzel. O grande desafio (The great debaters), EUA, 2007. Produzido por: Harpo Films, Marshall Production, Road Rebel, The Weinstein Company. 